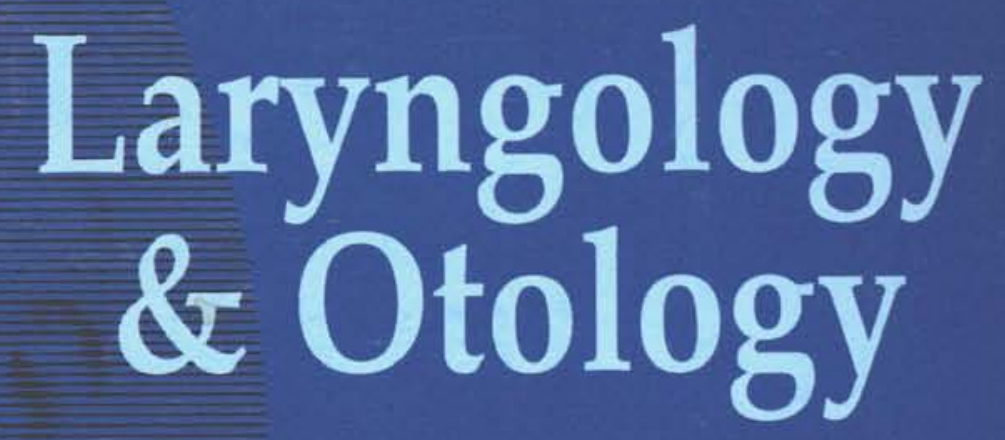

Emeritus Advisor in Pathology

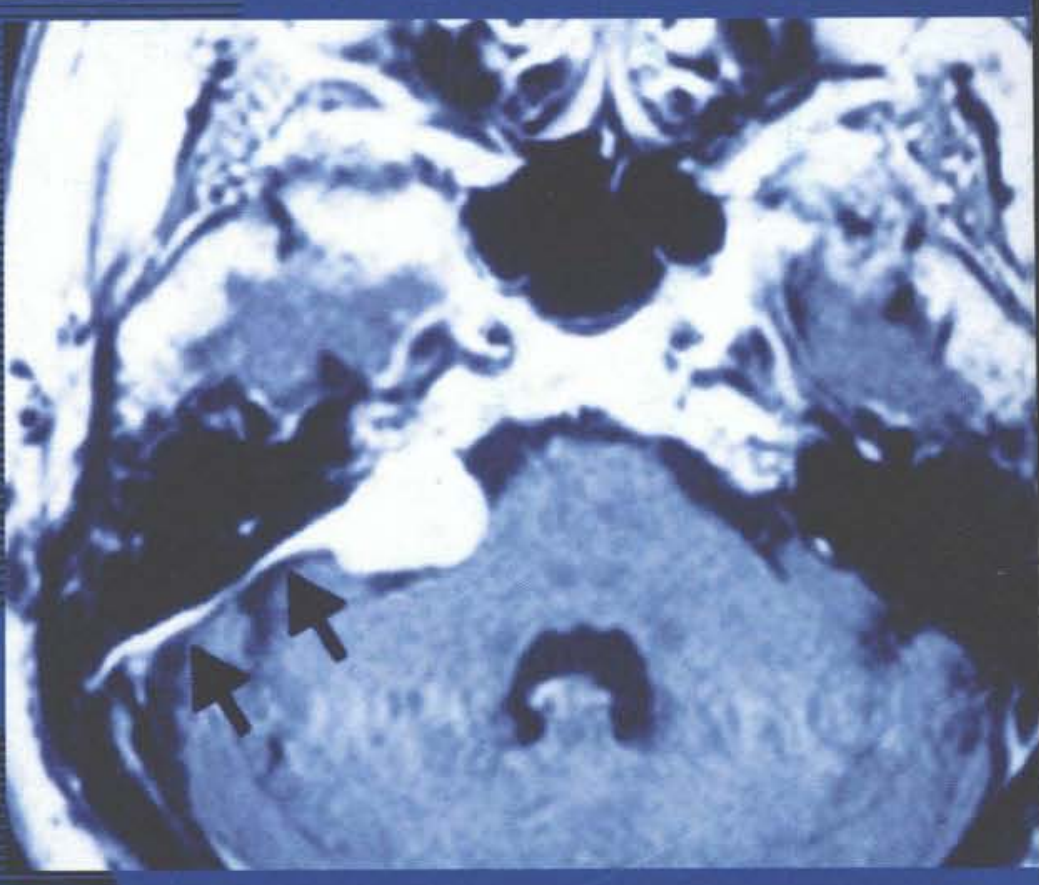
imaging and management

Horizontal glottectomy: funtion and oncological results Frey's syndrome treatment with botulinum toxin

Prophylaxis for venous thromboembolism in head and neck surgery 


\section{SURGICAL-QUALITY VIDEO IMAgING MAde AFFordable For THe OfFice}
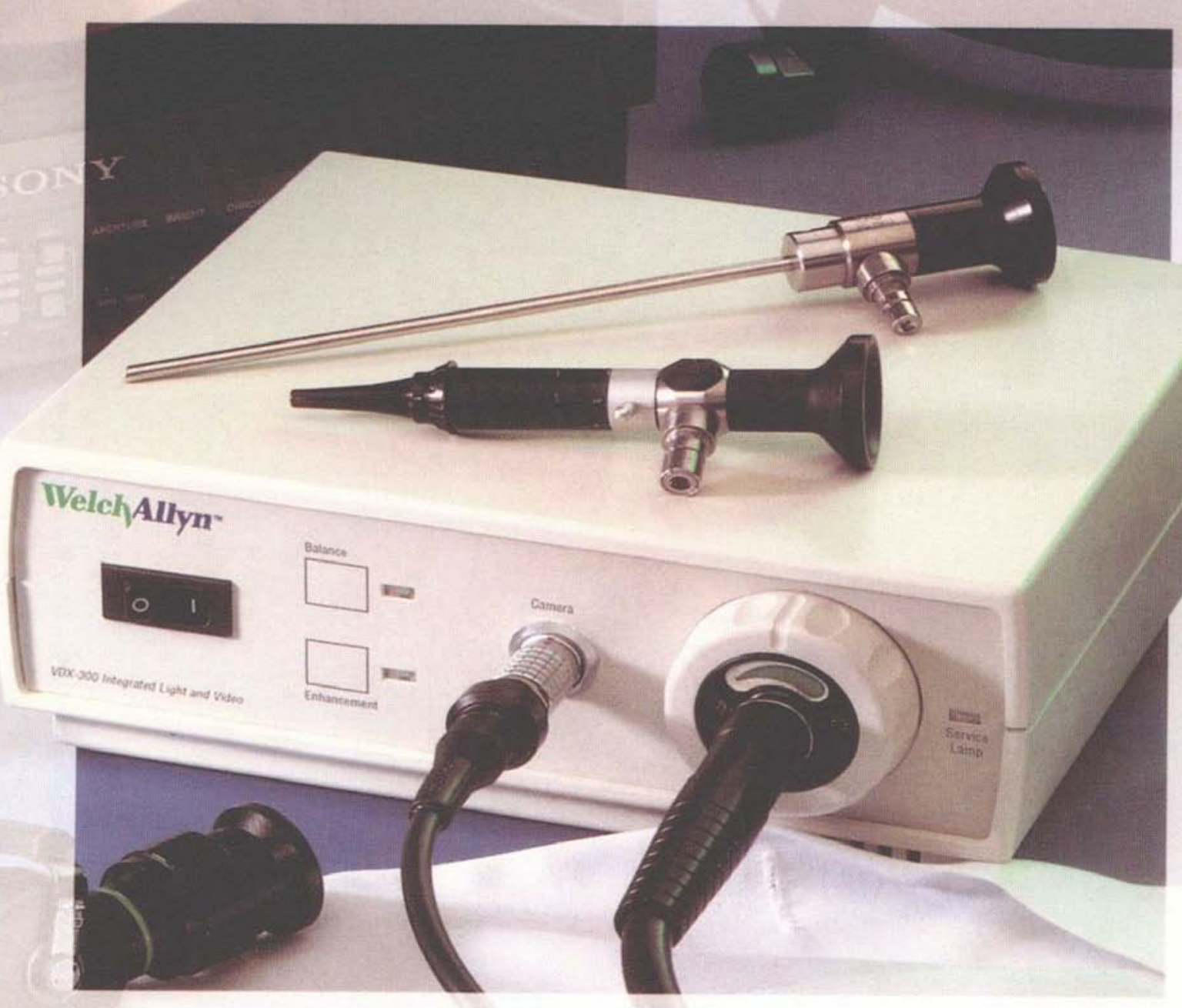

The value that video instruments bring to surgical settings is well-known. Now, with the new Welch Allyn VDX-300 Imaging and Illumination Platform, you can bring all the benefits of video into your office - at half the cost of current surgical video systems. By incorporating patented Welch Allyn Solarc ${ }^{\mathrm{m}}$ Lamp Technology, the Welch Allyn VDX. 300 is the only platform that can provide whiter, surgical-quality illumination $\left(5,500^{\circ} \mathrm{K}\right)$ at the price of halogen systems. The versatile Welch Allyn VDX-300 can turn nearly all your current optical instruments - flexible rhinolaryngoscopes, rigid sinuscopes, and more - into surgical-quality video instruments. And since the Welch Allyn VDX-300 is the only platform to integrate both the video processor and light source into one convenient unit, it is also the easiest system to use.

\section{TVelchAllyn}

For further information or a demonstration of the Welch Allyn VDX-300 system contact:

\section{GUYMARK UK}

Incorporating Houseman-Caltec INTERNATIONAL

London Office:

Midlands Office:

Calibration \& Service:
GUYMARK UK, Indalo House, 50 Heath Road, Caterham, Surrey, CR3 5RQ Tel: 01883346969 Fax: 01883346979

Gurmark UK, Gleneagles House, 2 Haden Park Road, Cradley Heath, B64 7HE Tel: 01384410848 Fax: 01384410898

GuYmark UK, 20 Branscombe Close, Kings Heath, Birmingham, B14 6PP Tel: 01214435777 Fax: 01214435999 


\title{
TIO The Journal of Laryngology and Otology
}

\author{
(Founded in 1887 by MORELL MACKENZIE and NORRIS WOLFENDEN)
}

Edited by NEIL WEIR and GUY KENYON

Assistant Editors CAROL WENGRAF, RICHARD RAMSDEN, DAVID PROOPS, VALERIE LUND, HENRY GRANT, ANDREW JONES, MICHAEL ROTHERA MARTIN BAILEY, LIAM FLOOD, PATRICK BRADLEY, NICK JONES \& IAIN SWAN

Production Editors GILLIAN GOLDFARB \& JENNIFER ALMOND

\section{INSTRUCTIONS FOR AUTHORS}

1. Original articles which have not been published elsewhere are invited and should be sent to the Editor. They are considered for publication on the understanding that they are contributed to this Journal solely. Reproduction elsewhere in whole or in part, is not permitted without the previous written consent of the Author and Editor and the customary acknowledgement must be made. Normally an original main article should not exceed 7500 words.

Longer articles or theses will be considered for publication as Supplements, at the expense of the authors or their employing authorities.

2. Manuscripts should be typewritten in duplicate on one side of the paper only (A4 $2973210 \mathrm{~mm}$ ) and double spaced, with wide margins.

Begin each component on a new page in the following sequence: title page, abstract, text, acknowledgements, references, tables and legends.

(a) Title page-Titles should be short with names of the authors, higher degrees only. Details of the departments in which the authors work should be put lower down. An address for correspondence should be supplied together with the author who should receive this; this will ultimately appear beneath the list of references. Any change of address should be notified. If the paper was presented at a meeting, the details of this must be given and will be inserted at the bottom of the first page of printed script.

(b) Abstract-This should contain not more than 150 words and include a statement of the problem, the method of study, results and conclusions; a 'summary' section should not be included in the main manuscript. No paper will be accepted without an abstract.

(c) Key Words-Only those appearing as Medical Subject Headings (MeSH) in the supplement to the Index Medicus may be used; where no appropriate word(s) are listed those dictated by common sense/usage should be supplied.

(d) Text-Suggested outline-11) introduction, (2) materials and methods, (3) results, (4) discussion, (5) conclusion.

(e) Tables are adjuncts to the text and should not repeat material already presented.

(f) Illustrations - Two sets of illustrations, one with each copy of the manuscript, must be submitted and all authors should remember that the single column width is $80 \mathrm{~mm}$. One set of illustrations should, therefore, not exceed this width and they should ensure that the essential features are illustrated within this dimension.

Coloured illustrations will be charged to authors, unless a special grant is authorized by the Editor.

Written permission from the publisher must be provided to the Journal in order to republish material with copyright elsewhere and also from the senior author where necessary. Consent to be obtained from a patient if a photograph of their face is to be reproduced.

(g) Measurements must be in metric units, with Système Internationale (SI) equivalents given in parentheses.

(h) References-For Journal articles, The Harvard system of recording references should be used, e.g. Green, C. and Brown, D. (1951) The tonsil problem. Journal of Lanyngology and Otology 65: 33-38. A paper written by more than two authors should be abbreviated in the text, e.g. Green et al. (1951), but all the authors should be given in the list of references. The titles of all Journals should be given without abbreviation. References should be listed in alphabetical order; use of the Vancouver system will not be accepted.

For single-author books, the following style should be used: Green, C. (1951) The tonsil problem, 2nd Edition. vol. 1, Headley Brothers Ltd., Ashford, Kent, pp 33-38.

For papers in multi-books with one or more editors, the reference should include the title of the chapter and the names of the editors, together with the number of the edition as e.g. Brown, D. (1951) Examination of the ear. In Diseases of the Ear, Nose and Throat. 2nd Edition. (White, A., Black, B., eds.), Headley Brothers Ltd., Ashford, Kent, pp 33-38.

It is most important that authors should verify personally the accuracy of every reference before submitting a paper for publication. The names of authors cited in the References should be given in alphabetical order.

(i) Drugs-The proper names of drugs must be used. One reference can be made to the brand name if it is felt to be important to the study

(j) Financial disclosures-In the submission letter to the Editor, the authors must list all affiliations with or financial involvement in, organizations or entities with a direct financial interest in the subject matter or material of the research discussed in the manuscript.

(k) Declaration. Each manuscript must be accompanied by a letter of declaration to be signed by each author to confirm that they have seen, read and approve the contribution bearing their name.

(1) Rejections-All manuscripts which are rejected will no longer be returned to the authors. Those submitting papers should, therefore, ensure that they retain at least one copy and the reference numbers, if any, of the illustrations. The only exception to this will be those manuscripts with colour illustrations which will be returned automatically by Surface Mail.

(m) Facsimile (FAX)-All authors should send a Facsimile number whenever possible to speed communication; this particularly applies to those outside the United Kingdom. Manuscripts with no visual illustrations (X-rays/pathology) may be sent by facsimile.

3. Page proofs are sent to authors for corrections, which should be kept to a minimum; they must be clearly marked, and no extra matter added. Proofs should be returned within 5 days.

4. Orders for reprints must be sent when returning page proofs, and for this purpose special forms are supplied.

5. Editorial communications may be addressed to The Editor, Joumal of Laryngology and Otology, c/o Headley Brothers Ltd., The Invicta Press, Ashford, Kent TN24 BHH, or sent by FAX $(01483$ 451874).

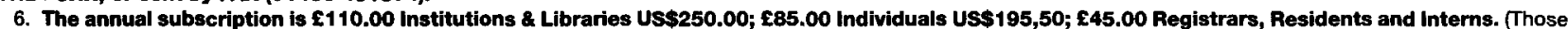
in training should submit a certificate from The Head of the Department giving details of their appointment; those who qualify must supply their home address for mailing direct). Claims to be made for missing issues within 6 months of each publication date.

7. Single copies of current or back numbers (when available) will be on sale at $\$ 12.00$ each (including postage).

8. SUPPLEMENTS published at 'irregular' intervals with subscription, available separately on request.

9. All subscriptions, advertising and business communications should be sent to the publishers, or subscription agents.

Instructions for Occasional Articles

Review Articles. Articles of this type, preferably not exceeding 3,000 words will be considered but the author(s) are expected to be a recognized authority on the Review Articles. Articles of this type, preferably not exceeding 3.0

topic and have carried out work of their own in the relevant field. Historical Articles. Articles of this type are generally encouraged, but it is obvious that they have to provide some new information or interpretation, whether it be
about a well-known person or for example an instrument associated with him, but those from within a Hospital's own department who have made a hitherto less about a well-known person or for example an Audit Articles. Articles should be of general audit interest-not specifically departmental. It should always be demonstrated that the 'audit cycle' has been

completed.

'Silence in Court'. Articles on medicolegal topics are welcome but a preliminary letter written beforehand is requested to ensure that the contribution would be appropriate.

Short Communications. This feature will be used on an occasional basis. Examples of material suitable for inclusion under this title would be, for example, a piece of work which was of clinical interest but had failed to produce findings which were of statistical significance; where an investigative technique has been applied to an allied field, not warranting a further in-depth description of its earlier application and methodology.

Radiology in Focus. Short reports on cases in which the radiology has been crucial in the making of the diagnosis or the management of a particular case now appear on a monthly or bimonthly basis. This spot is to encourage clinicians and radiologists to produce material of particular interest in the specialty and to appear on a monthly or bimonthly basis. This spot is to encourage clinicians and radiologists to produce material of particular interest in the specialty and to A this field. Only presentation Pathology in Focus. Articles which are of pathologith particular emphasis on the way the diagnosis was achieved now appear on a monthly or bimonthly basis. It is hoped that clinicians will involv their pathologists in these reports, and all illustrations must be of first-class quality. Where a department particularly those overseas, may not have such specialized facilities. It may be possible, if a block or several unstained sections are provided for our Adviser to produce or supplement the illustration submitted. Only contributions of particular pathological interest will be accepted.

Oncology in Focus. This new feature is for papers concerned with oncological treatment and investigation.

Letters to the Editor. This feature has been re-introduced to give those who wish to comment about a paper previously published within the Journal, an opportunity to express their views. Wherever possible, the original author is asked to add his further comment, thereby adding to the value of the contribution. Such letters should be sent as soon as possible after publication of each month's issue of the Journal in the hope of including them early thereafter.

'Mini-papers', such as those which appear in the British Medical Journal, Lancet, or New England Journal of Medicine, will not be acceptable except on the rare occasion that they bring information of immediate interest to the reader.

HEADLEY BROTHERS LTD, THE INVICTA PRESS, ASHFORD, KENT

(C) Journal of Laryngology and Otology Ltd. 1997 ISSN 0022-2151

Periodicals Postage Paid at Rahway N.J.

Postmaster. Send address corrections to The Journal of Laryngology and Otology, clo Mercury

Airfreight International Lid. Inc., 2323 Randolph Avenue, Avenel, N.J. 07001. Frequency of Publication: Monthly. 


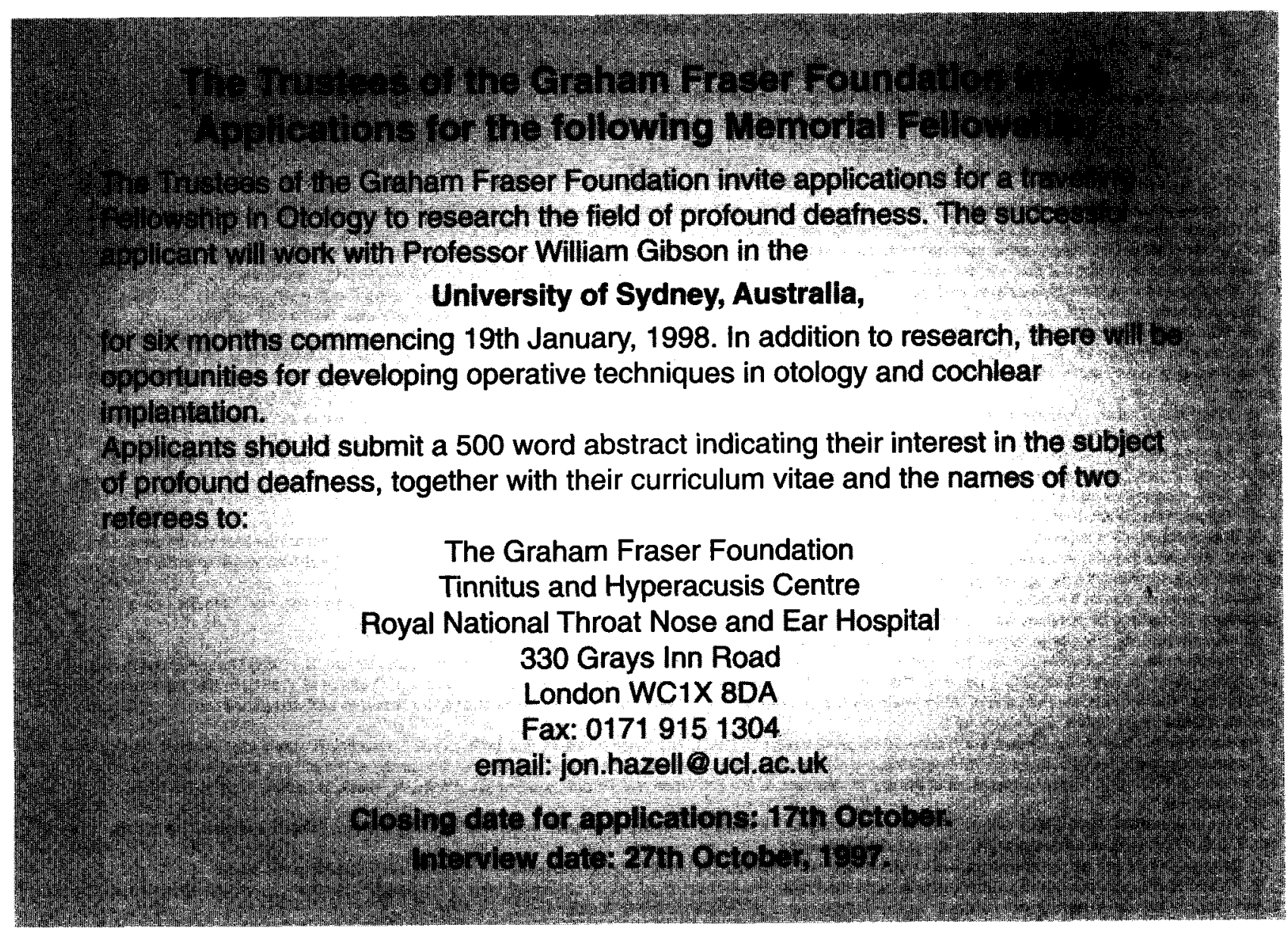

\section{4th European Symposium Paediatric Cochlear Implantation 14th - 17th June 1998 \\ 's-Hertogenbosch, The Netherlands}

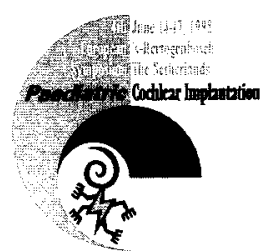

An international faculty will highlight the most important developments in the field of Paediatric Cochlear Implantation. The main topics will be: long-term results, speech and language development, medical aspects, objective measurements, social and emotional development, technical developments, ethical issues and dilemmas. Opportunity for free papers and posters.

For further information:

Prof. Paul van den Broek Department ORL

University Hospital Nijmegen PO Box 9101

$6500 \mathrm{HB}$ Nijmegen

The Netherlands

Fax: +31 243540251

E-mail: P.VandenBroek@kno.azn.nl
B.A.P.O.

British Association for Paediatric Otorhinolaryngology

\section{ANNUAL MEETING}

\section{Friday 10 October 1997 Nottingham}

Cost: $£ 25$ (to include $£ 15$ to Fellowship Fund)

Meeting and Membership enquiries:

David Albert

234 Great Portland Street, London W1N 5PH

Telephone: 0171-390 8300

\section{Abstracts to:}

Kevin Gibbin

Queens Medical Centre, Nottingham NG7 2UH

Telephone: 0115-970 9275

Deadline: 31 July

Format: 1 side A4 (12 point)

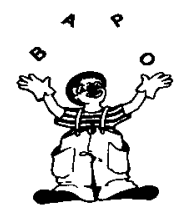




\section{Superb new Endoscopic Sinus Surgery Package!}

\section{Singular is proud to announce publication of a superb new CD-ROM - Atlas - Video package that was the talk of the show during IFOS 1997 in Sydney.}

\section{Endoscopic Sinus Surgery New Horizons \\ Nikhil J Bhatt, M.D.}

A fill colour atlas that provides an in-depth exploration of the development of endoscopic sinus surgery. It presents cross-sectional surgical anatomy and its radiological correlations on CT scans and demonstrates, through clear photographs, standard endoscopic sinus surgical techniques with surgical significance of the anatomical landmarks.

Contents: Introduction, Coronal-Sectional Anatomy with CT Section Correlations. Regional Surgical Anatomy. Minimally Invasive Techniques in Endoscopic Sinus Surgery. Surgical Techniques for Turbinates and Anatomical Variants (Group I). Surgical Techniques for Ostiomeatal Unit Obstruction (Group II). Endonasal Approach to the Frontal Sinus (Groups III A \& B). Sphenoid Sinus Surgery (Groups III A \& B). Minimally Invasive Techniques in Paediatric Sinus Diseases. Adjuvant Procedures.

August 1997190 pages 1-56593-897-6

Hardcover $\left(8 \frac{1}{2} \times 11\right) \quad \mathbf{8 5 5 . 0 0}$

Companion videos to Endoscopic Sinus Surgery: New Horizons

\section{Minimally Invasive Surgical}

\section{Techniques}

- Demonstrates minimally invasive techniques for anatomical variants, ostiomeatal unit disease, endonasal approach to the frontal and sphenoid sinus diseases

- Provides live surgical procedures covered in the book. Endoscopic Sinus Sungery: New Horizons

Volume I - Laser Surgical techniques

Contents: Turbinate Reduction and Turbinotomy. Conchoplasty and Turbinoplasty. Middle Meatus Reconstruction with Partial Middle Turbinotomyd Partial Uncinectomy and Infunibulotomy with Maxillary Ostium Reconstruction. Anterior Ethmoidectomy and Bulla and Suprabullar Cell Resection. Frontal Recess and Frontal Ostium Reconstruction. Revision Surgery. Sphenoidotomy. Sphenoethmoidectormy. Paediatric Sinus Surgery. Dacryocystorhinostomy.

PAL Video August 1997 Running time $30 \mathrm{~min}$. $1-56593-900-X \quad £, 65.00$ plus VAT Volume II - Microdebrider Surgical Techniques Contents: Inferior Turbinotomy - Reduction. Middle Meatus Reconstruction with Partial Middle Turbinotomy. Partial Excision of Concha Bullosa. Partial Uncinectomy and Infundibulotomy with Maxillary Ostium Reconstruction. Total Uncinectomy and Agger Cell
Resection. Anterior Ethmoidectomy and Bulla and Suprabullar Cell Resection. Basal Lamella and Posterior Ethmoidectomy. Sphenoidotomy. Frontal Recess and Frontal Ostium Reconstruction. Dacryocystorhinostomy.

PAL Video August 1997 Running time $30 \mathrm{~min}$. 1-56593-901-8 $\quad 65.00$ plus VAT

Atlas-Video Value Pack - Book plus two videotapes £185.00 (Saves $£ 20.00$ )

Video Value Pack - Two pideotapes $£ 117.50$

(Saves $\varliminf^{12.50)}$

\section{Interactive CD-ROM}

- Clearly demonstrates nasal and paranasal sinus pathology in adults and children along with diagnostic criteria and specific treatments.

- Allows viewer to rapidly select and study specific areas(s) of interest using keywords, hypertext links and more.

- Contains clear and concise explanatory text, colour illustrations and endoscopies, plus narrated video clips on minimally invasive techniques for anatomical variants, ostiomeatal unit disease, endonasal approach to the frontal, and sphenoid sinus diseases.

\section{Endoscopic Sinus Surgery CD-ROM Volume}

Contents: Surgical Significance of the Anatomical Landmarks and Surgical Techniques. Coronal-Sectional Anatomy with CT Section Correlations. Regional Surgical Anatomy. Minimally Invasive Techniques in Endoscopic Sinus Surgery. Microdebriders and Lasers. Surgical Techniques for Turbinates and Anatomical Variants. Surgical Techniques for Ostiomeatal Unit Obstruction.

\section{Endoscopic Sinus. Surgery CD-ROM Volume II}

Contents: Endonasal Approach to the Frontal Sinus. Sphenoid Sinus Surgery. Minimally Invasive Techniques in Paediatric Sinus Diseases. Adjuvant Procedures. Computer Guided Endoscopic Sinus Surgery.

Two CD-ROM set $£ 110.00$ plus VAT

(For both MAC and PC)

Atlas-CD-ROM Value Pack - Atlas plus two CD-ROMs 6185.00 (Saves $\mathbf{2 0 . 0 0}^{20}$

Combo Value Pack - Atlas, two videotapes plus two CD-ROMs 6265.00 (Saves $\left.£^{80.00}\right)$

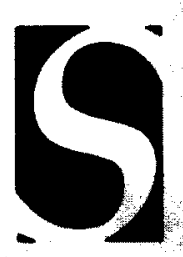

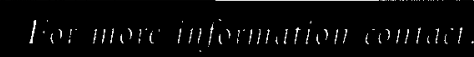 Singular Publishing Ltd

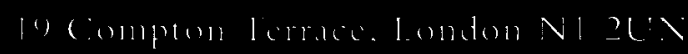

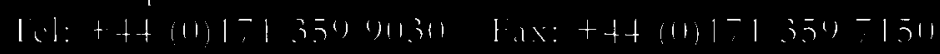

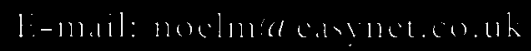




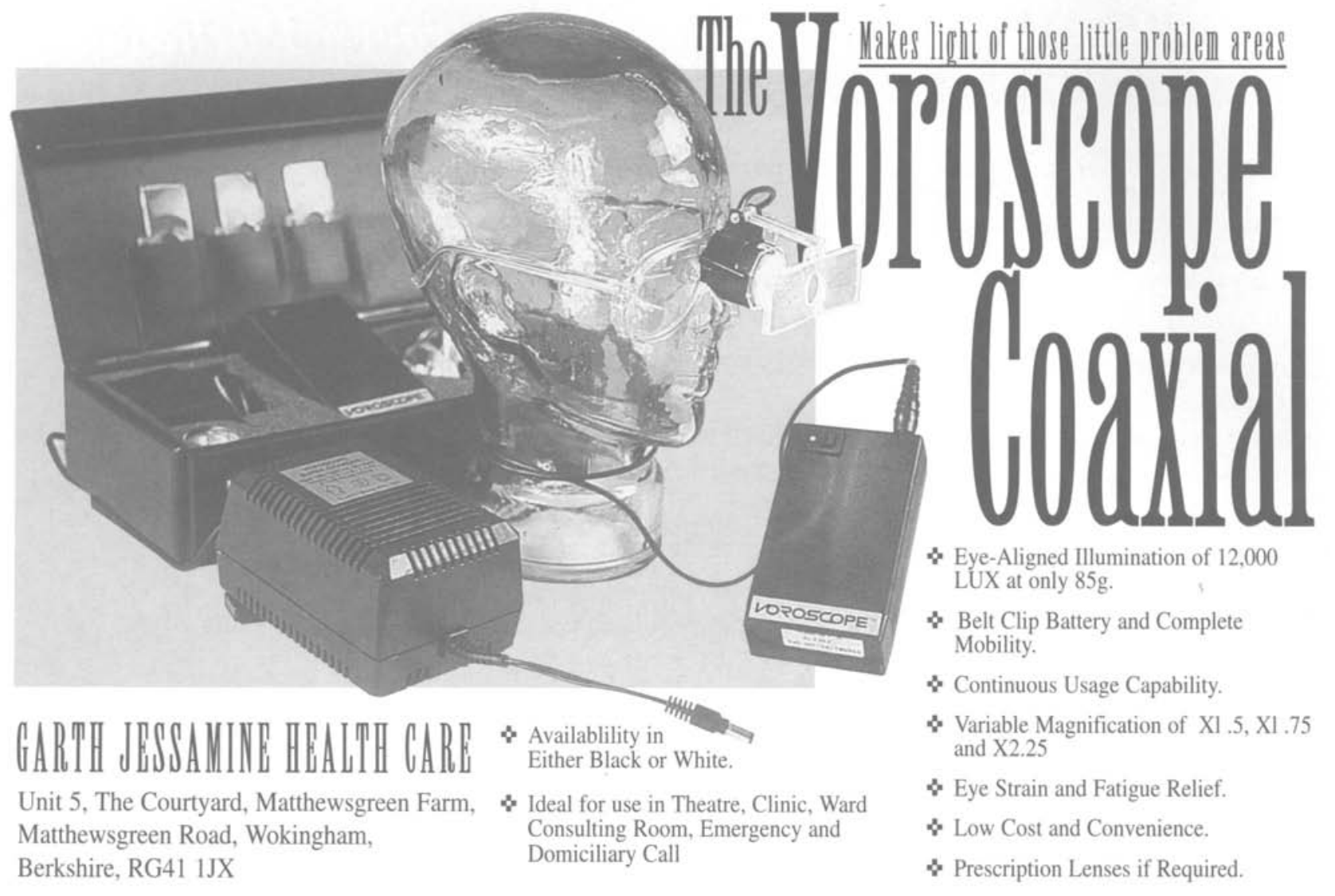

\section{Telephone: (01734) 786916 Pax: (01734) 774064}

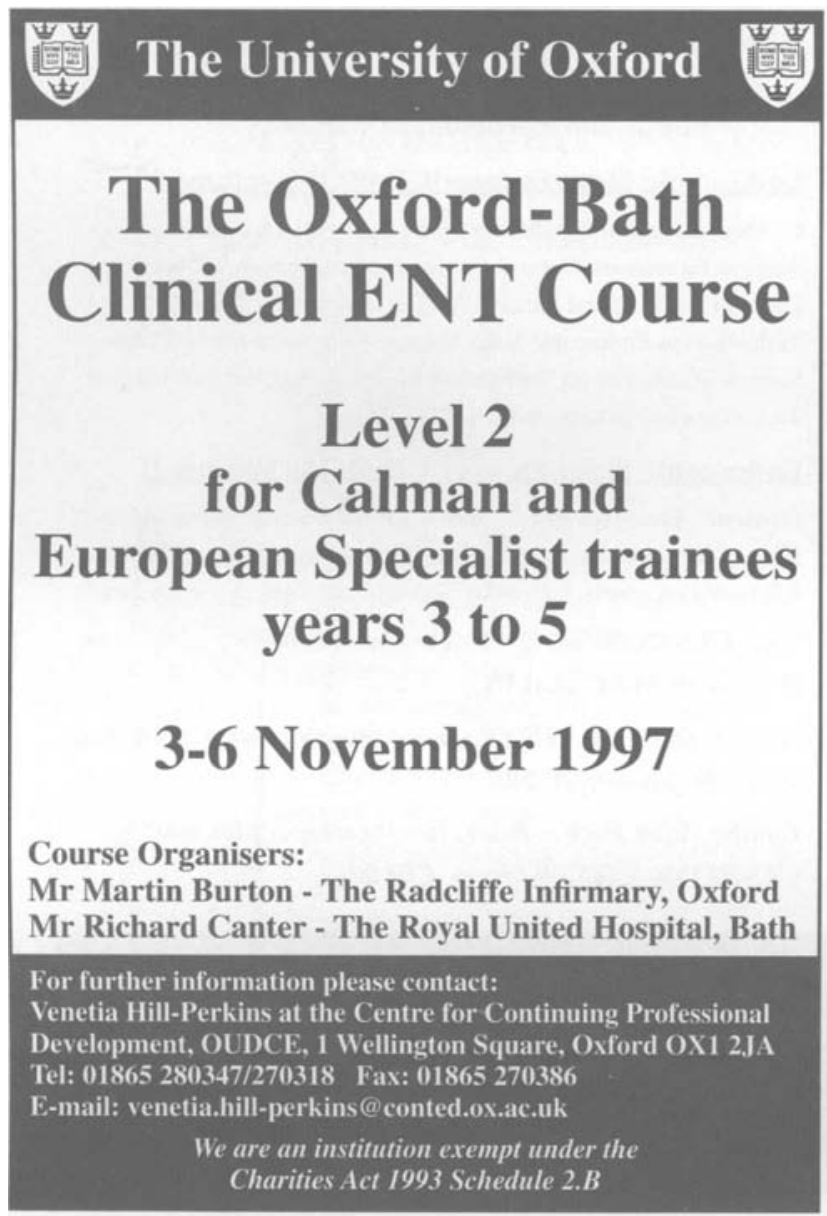

\section{Temporal Bone Surgical Dissection Course}

GEORGIA EAR INSTITUTE

- Designed for practicing otolaryngologists and senior residents in training

- Includes lectures and temporal bone dissection

- All specimens and instruments provided

Courses - 1997

October $20-24$

Courses - 1998

Jamiary 19-23, May $18-22$,

September $14-18$, November $16-20$

Fee: Physicians - $\$ 800$ - Residents - $\$ 350$ CME Credits: 50 Hours

COURSE DIRECTORS:

M. MIIES GOUDSMIT, MD, FACS

MALCOLM D. GRAHAM, MD, FACS

For funther information contact.

Shiritey Johnson, RN, MSA - Mectical Education Deparment

P.O. Box 23089 - Savanmah, Georgia 31403-3089

912-350-7365 - Fax 912-350-8998

MEMORIAL

MEDICAL CENTER

SAVANNAH, GEORGIA USA 

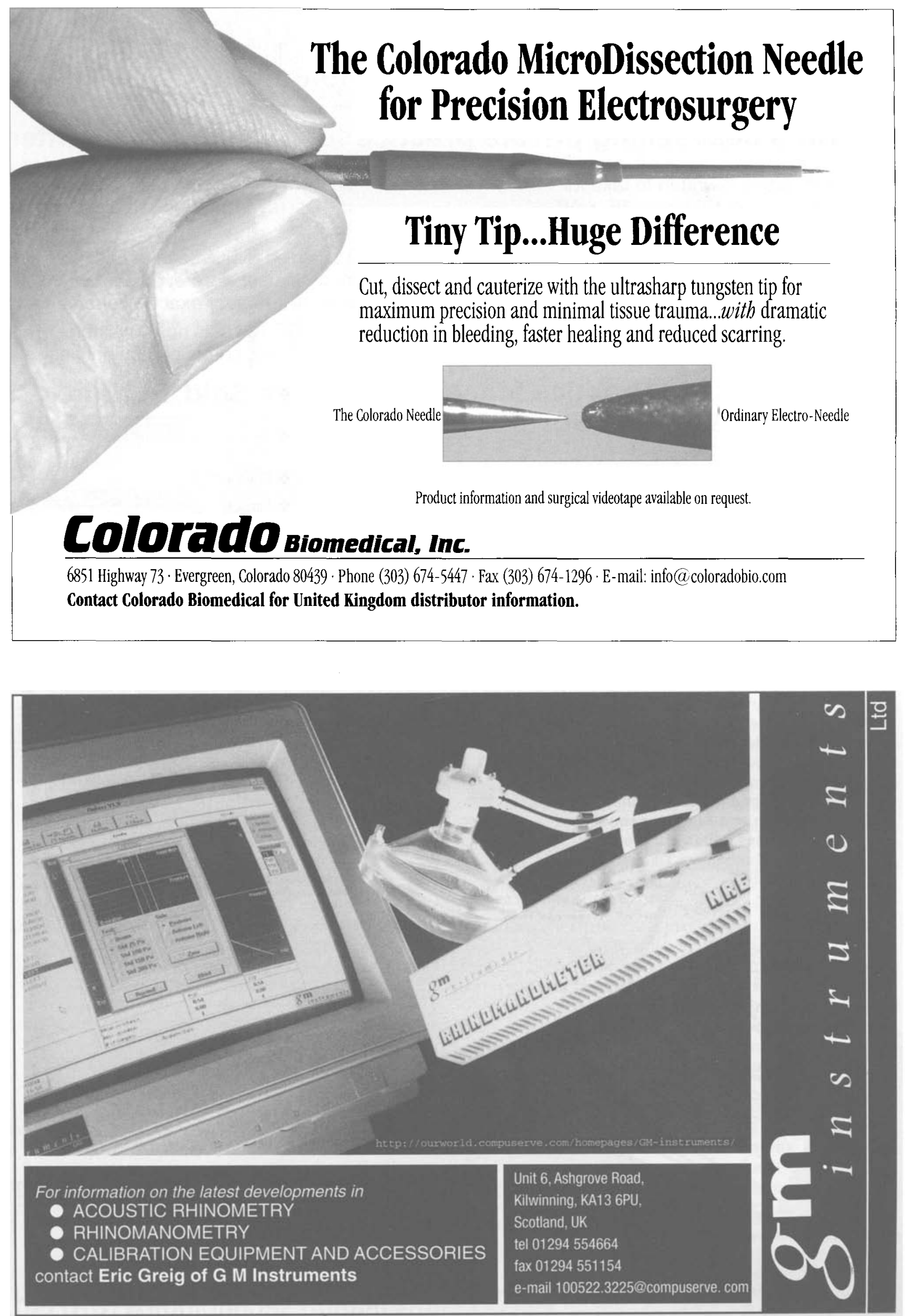


\section{Private Practice Software \\ From D.G.L. Information Technologies (UK) Ltd.}

\section{The UK's best selling private practice software, just got better...}

Completely rewritten to take full advantage of Windows '95 \& NT.

New modular version provides a tailored, cost-effective solution whatever your budget or requirements.

Major new features have been added that offer an unrivaled range of features and flexibility.
Ready for Electronic Claims Processing and approved by major participating Insurers.

Acclaimed for it's ease of use, we have made the software even easier to use and tailor to your exact requirements. BEST OF ALL it is now available, FREE, on a 30-day, no-obligation trial basis.

\section{Over 1300 Practice Manager Licences Sold To-date.}

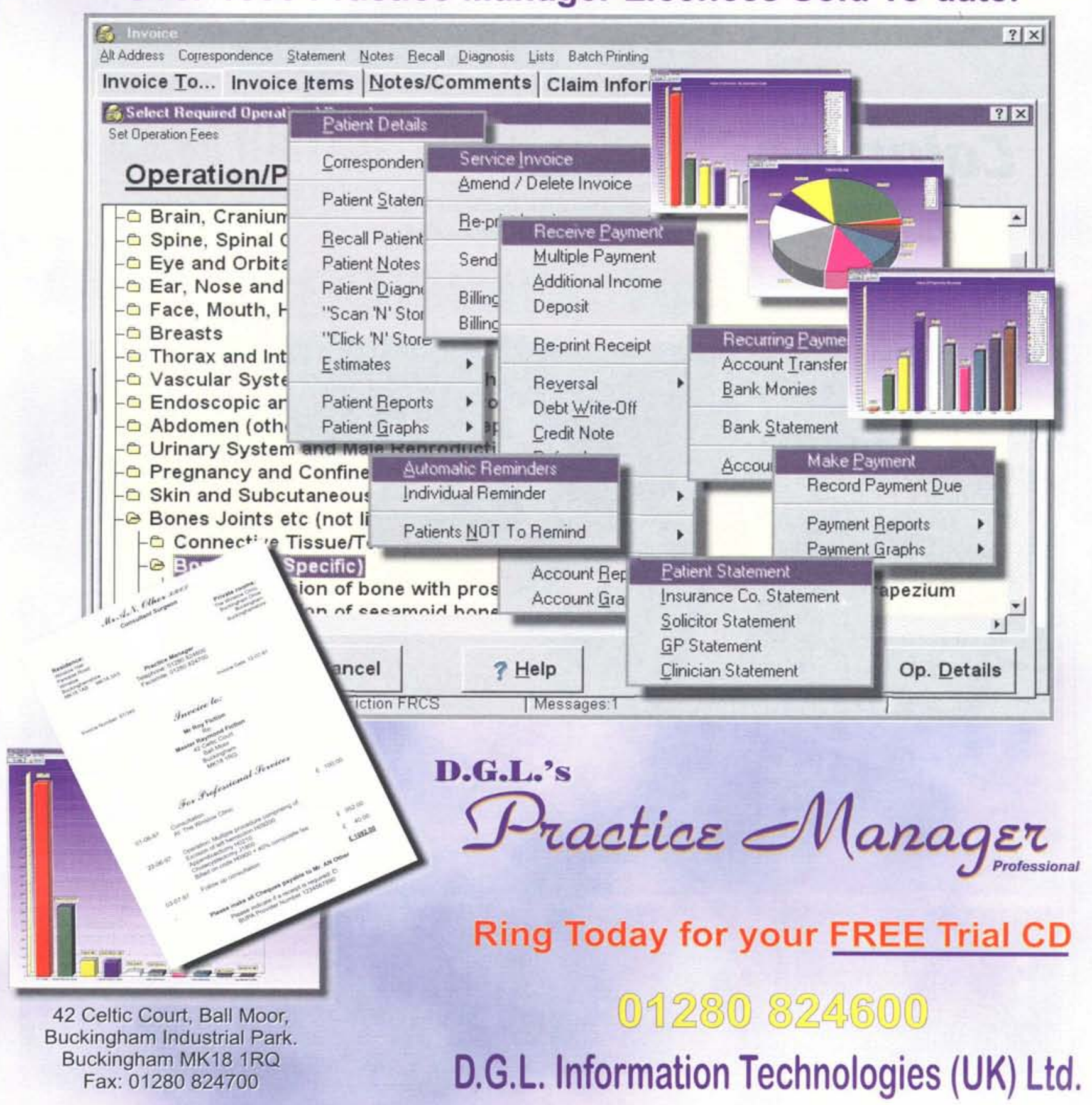

